\title{
Antioxidative Activity of Alcoholic Beverages made from Purple Rice (Oryza sativa
}

\section{var. Indica cv. Shiun)}

\author{
Masanori Koguchi, Noriaki Saigusa and Yuji Teramoto* \\ Department of Applied Microbial Technology, Sojo University, Ikeda 4-22-1 Kumamoto 860-0082, Japan
}

Received March 25, 2009; Accepted December 29, 2009

\begin{abstract}
Alcoholic beverages made from purple rice grains contained 11.0 to $11.5 \%$ (v/v) ethanol and a higher amount of phenolic compounds. Alcoholic beverages made from purple rice grain were brilliant red, similar to the color of red wine, especially those made from uncooked purple rice. The amount of anthocyanin in beverages made from cooked and uncooked rice was 36 and $88 \mu \mathrm{g} / \mathrm{mL}$, respectively. The DPPH radical scavenging activity of the alcoholic beverages made from purple rice was much higher than that of beverages made from ordinary brown and polished rice. The lipid peroxidation inhibitory activity of the alcoholic beverage made from uncooked purple rice was also the strongest. In the course of this study, we produced purple rice wine that was red and exhibited antioxidative activity.
\end{abstract}

Keywords: antioxidative activity, purple rice, anthocyanin, alcoholic beverage

\section{Introduction}

As progress is made in fermentation technology and the brewing industry, many kinds of alcoholic beverages are being produced each year to catch the interest of consumers. In Japanese sake brewing, the cooking of rice grains is an important process. Rice bran, which contains proteins, lipids, vitamins, and minerals, is usually removed from the rice grains by polishing before fermentation to produce an alcoholic beverage of good quality.

Purple rice (Oryza sativa var. Indica cv. Shiun), however, contains anthocyanin pigments, such as cyanidin and peonidin glucosides, in the bran layer. Anthocyanin is known to have physiological functions, as it has antioxidative activities, contributes to the prevention of arterial sclerosis, and is a type of functional food. Furthermore, anthocyanins in purple-fleshed sweet potato are known to have physiological functions, such as antioxidant properties (Furuta et al., 1998), antimutagenicity (Yoshimoto et al., 1999), and the ability to provide relief from liver injury (Suda et al., 1997).

Teramoto et al. (1994) reported that the quality, in terms of both aroma and taste, of purple rice wine made with uncooked, unpolished purple rice was much higher than that of rice wine made with cooked, unpolished purple rice. Addi-

*To whom correspondence should be addressed.

E-mail: yuji@bio.sojo-u.ac.jp tionally, the characteristics of purple rice wine economically produced in an uncooked ethanol fermentation system have previously been reported (Saigusa et al., 1994).

In this study, we investigated the antioxidant activity of alcoholic beverages made from uncooked, unpolished purple rice, designated as purple rice wine. For comparison, fermentation was carried out with cooked and uncooked rice. Rice wine was also made from ordinary brown rice and polished rice grain.

\section{Materials and Methods}

Rice grains Purple rice (Oryza sativa var. Indica cv. Shiun) was purchased from Kajiwara Beikoku Co., Ltd. (Kyoto, Japan). Commercial ordinary brown rice (Oryza sativa var. Akitakomati) and ordinary polished rice (Oryza sativa var. Koshihikari) were also used for brewing rice wines. Rice grains were ground to particles of 2-3 $\mathrm{mm}$ in diameter by an electric grinder (Kansai Toki model "Hikikko K-80") before ethanol fermentation.

A number of reports concerning alcoholic beverages made from rice grains of Oryza sativa var. Indica cv. Shiun have been published by our research team, and in which this rice grain is designated as red rice in a broad sense (Teramoto et al., 1994; Saigusa et al., 1994). Currently, a large number of rice species are cultivated, studied, and classified; properly speaking, the Shiun rice, which contains anthocyanin in 
the bran layer, should be called purple rice, and the term red rice should be used for rice which contains tannin in the bran layer. For this study, the term purple rice was used for the grains of Shiun.

Enzyme preparation and yeast strain Sumizyme, a glucoamylase preparation made from Rhizopus sp. (Shinnihon Kagaku Kogyo Co., Ltd., Anjo, Japan), was used as the saccharifying agent. Saccharomyces cerevisiae kyokai No.7 was used for ethanol fermentation.

Chemicals 1,1-Diphenyl-2-picrylhydrazyl (DPPH) was purchased from Nacalai Tesque (Kyoto, Japan). Trolox (6-hydroxy-2,5,7,8-tetramethyl-chroman-2-carboxylic acid) and $\beta$-carotene were purchased from Sigma-Aldrich, Inc. (St. Louis, MO, USA). 2,6-Di-tert-butyl-p-cresol (BHT) was purchased from Tokyo Kasei Co., Ltd. (Tokyo, Japan).

Procedure for ethanol fermentation The procedure for ethanol fermentation with cooking is shown in Figure 1. Thirty grams of unpolished purple rice, ordinary brown rice, or ordinary polished rice and $50 \mathrm{~mL}$ of deionized water were dispensed into a $300 \mathrm{~mL}$ Erlenmeyer flask and autoclaved at $121^{\circ} \mathrm{C}$ for $15 \mathrm{~min}$. After cooling, the resulting cooked rice was mixed with $0.2 \mathrm{~g}$ of Sumizyme, $40 \mathrm{~mL}$ of deionized water, and $10 \mathrm{~mL}$ of a yeast suspension, which readily made the population of yeast in the initial mash to be $3.0 \times 10^{7}$ cells/ $\mathrm{mL}$. The $\mathrm{pH}$ of the initial mash was adjusted to 4.0 using lactic acid. Ethanol fermentation was conducted at $25^{\circ} \mathrm{C}$ in the dark.

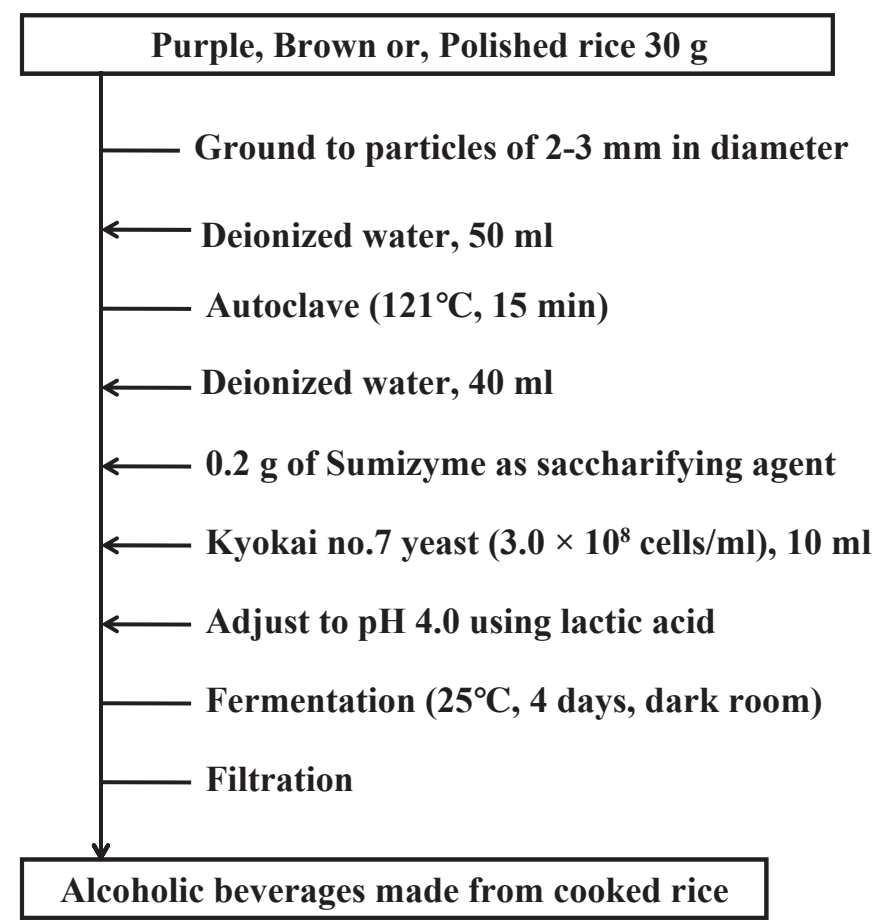

The procedure for ethanol fermentation without cooking is shown in Figure 2. Thirty grams of unpolished raw purple rice, ordinary raw brown rice, or ordinary raw polished rice and $90 \mathrm{~mL}$ of deionized water, $0.2 \mathrm{~g}$ of Sumizyme, and 10 $\mathrm{mL}$ of a yeast suspension were dispensed into a $300 \mathrm{~mL} \mathrm{Er}$ lenmeyer flask. The population of yeast in the initial mash was adjusted to $3.0 \times 10^{7}$ cells $/ \mathrm{mL}$. The $\mathrm{pH}$ of the initial mash was adjusted to 4.0 using lactic acid, and fermentation was conducted in the same manner as for ethanol fermentation with cooking.

The decrease in weight of the entire Erlenmeyer flask and its contents as a result of evolution of $\mathrm{CO}_{2}$ gas was measured every $24 \mathrm{~h}$.

Analysis of ethanol concentration Ethanol concentration was determined by gas chromatography using a gas chromatograph (model GC-14A; Shimadzu Co., Kyoto) equipped with a $3.1 \mathrm{~m}$ PEG-HT column (Gasukuro Kogyo Inc., Tokyo).

General analytical methods After fermentation, the mash made from purple, ordinary brown, or polished rice was filtered through No.101 filter paper (Advantec Toyo Co., Ltd., Tokyo, Japan), and the resulting rice wine was analyzed.

Acidity was measured by titrating $10 \mathrm{~mL}$ of rice wine with $0.1 \mathrm{~N} \mathrm{NaOH}$. Reducing sugar as glucose was determined according to the methods of Somogyi and Nelson (Somogyi, 1952; Nelson, 1944). Total phenol compounds,

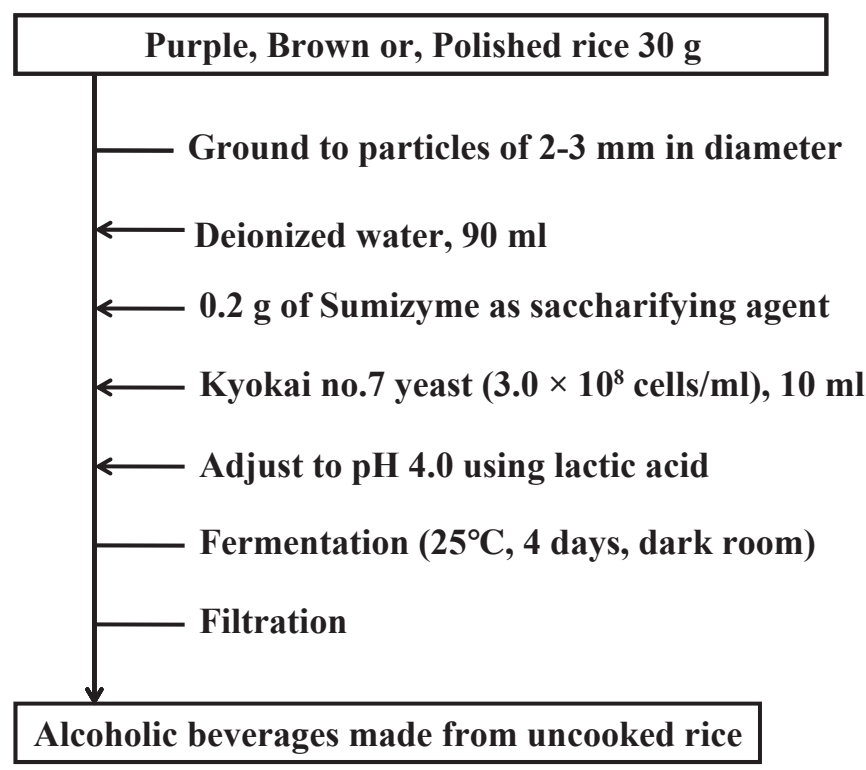

Fig. 2. Procedure for rice wine brewing without cooking.

Fig. 1. Procedure for rice wine brewing with cooking. 
such as gallic acid, were determined according to the FolinCiocalteu method (Singleton et al., 1999; Hamasaka et al., 2004).

Rice wine was filtered through a membrane filter with a pore size of $0.45 \mu \mathrm{m}$ and $47 \mathrm{~mm}$ in diameter (Advantec Toyo Co., Ltd., Tokyo, Japan). In order to determine the color quality, the resulting filtrate was examined using the Color Meter model ZE 2000 (Nihon Denshoku Kogyo Co., Ltd., Tokyo, Japan). The color quality of the rice wine was examined using the Hunter value L, a, and b color scale. To determine the absorption spectra, the resulting filtrate was diluted 50-fold with $1 \mathrm{~N} \mathrm{HCl}$ and applied to the Spectrophotometer model U-3010 (Hitachi, Tokyo, Japan).

The anthocyanin content of rice wine, as the cyanidine 3-glucoside equivalent $(\mu \mathrm{g} / \mathrm{mL})$, was measured according to the method of Boyles et al. (1993).

Determination of antioxidative activity The DPPH radical scavenging activity, as the Trolox equivalent, was measured on the basis of the method of Yamaguchi et al. (1998). The lipid peroxidation inhibitory activity, as the BHT equivalent, was determined using $\beta$-carotene (Hamasaka et al., 2004).

\section{Results and Discussion}

The fermentation curves of the mash made from various rice grains are shown in Figure 3. The characteristics of alcoholic beverages made from various rice grains are shown in Table 1. The final amount of the $\mathrm{CO}_{2}$ output was 10.1 to $11.3 \mathrm{~g}$, and the ethanol concentration of the beverages was 11.0 to $12.3 \%(\mathrm{v} / \mathrm{v})$.

Alcoholic beverages made from unpolished purple rice grains contained higher amounts of phenolic compounds.

The amount of anthocyanin contained in the beverages made from cooked and uncooked purple rice was 36 and 88 $\mu \mathrm{g} / \mathrm{mL}$, respectively.

Alcoholic beverages made from purple rice grain had a red color; in particular, that made from uncooked purple rice grain was brilliant red, just like red wine. The Hunter a value indicates the intensity of the red color; that of beverages made from cooked and uncooked purple rice grain was 2.01 and 5.72 (Table 2). On the other hand, the Hunter a value of the beverages made from ordinary brown rice and polished rice grains was negative. The Hunter $b$ value indicates the intensity of the yellow color; that of beverages made from cooked and uncooked purple rice grain was 6.01 and 3.92, respectively. Finally, the Hunter L value indicates the degree of brightness; that of beverages made from uncooked purple rice grains was lower. These results indicate that the beverage had a deep red color, just like a full-bodied red wine.

Figure 4 shows the absorption spectra of the beverages made from cooked and uncooked purple rice grain. The beverage made from cooked rice grain showed absorbance at $530 \mathrm{~nm}$. Part of the anthocyanin might decompose during the cooking process because alcoholic beverages made from
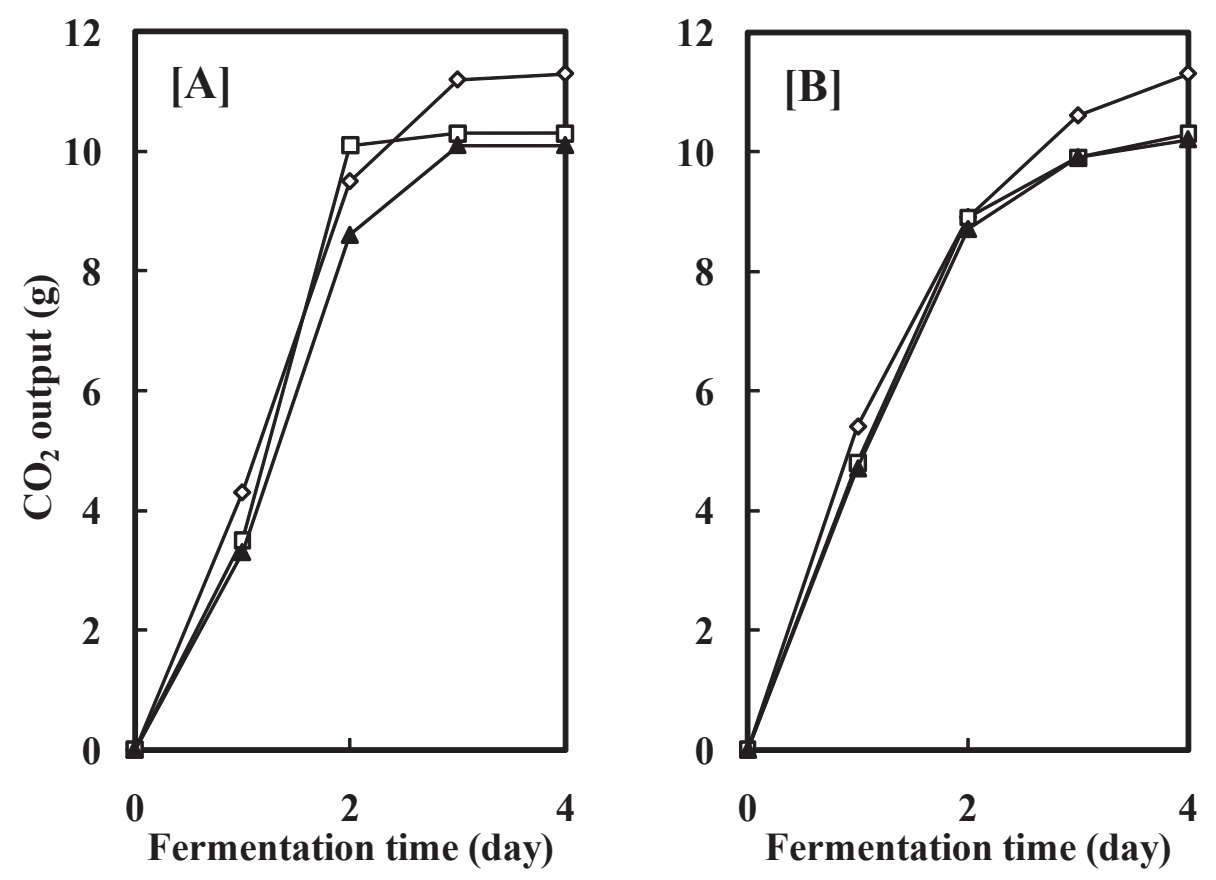

Fig. 3. Time courses of mash fermentation of various rice grains with $[\mathrm{A}]$ or without $[\mathrm{B}]$ cooking. $\boldsymbol{\Delta}$, purple rice; $\square$, brown rice; $\diamond$, polished rice. Values are the mean of three replicates. 
Table 1. Characteristics of alcoholic beverages made from various rice grains.

\begin{tabular}{|c|c|c|c|c|c|c|}
\hline & \multicolumn{2}{|c|}{ Purple rice } & \multicolumn{2}{|c|}{ Brown rice } & \multicolumn{2}{|c|}{ Polished rice } \\
\hline & Cooked & Uncooked & Cooked & Uncooked & Cooked & Uncooked \\
\hline Initial $\mathrm{pH}$ & 4.0 & 4.0 & 4.0 & 4.0 & 4.0 & 4.0 \\
\hline Final $\mathrm{pH}$ & 4.2 & 4.3 & 4.1 & 4.2 & 3.8 & 3.9 \\
\hline $\mathrm{CO}_{2}$ output $(\mathrm{g})$ & 10.1 & 10.2 & 10.3 & 10.3 & 11.3 & 11.3 \\
\hline Total volume $(\mathrm{mL})$ & 117 & 121 & 118 & 122 & 118 & 118 \\
\hline Filtrate $(\mathrm{mL})$ & 73 & 76 & 76 & 75 & 85 & 89 \\
\hline Acidity $(\mathrm{mL})$ & 4.1 & 3.4 & 3.1 & 2.6 & 3.1 & 3.2 \\
\hline Ethanol concentration $(\%, \mathrm{v} / \mathrm{v})$ & 11.5 & 11.0 & 11.4 & 11.0 & 12.3 & 12.3 \\
\hline Reducing sugar content $(\mu \mathrm{g} / \mathrm{mL})$ & 955 & 786 & 686 & 436 & 641 & 402 \\
\hline Total phenolic compound $(\mu \mathrm{g} / \mathrm{mL})$ & 689 & 871 & 332 & 331 & 238 & 440 \\
\hline Anthocyanin content $(\mu \mathrm{g} / \mathrm{mL})$ & 36 & 88 & ND & ND & ND & ND \\
\hline
\end{tabular}

Values are the means of three replicates.

ND, Not detected.

Table 2. Hunter value of alcoholic beverages made from various rice grains.

\begin{tabular}{ccccc}
\hline \multirow{2}{*}{ Sample } & & \multicolumn{3}{c}{ Hunter value } \\
\cline { 3 - 5 } & & $\mathrm{L}$ & $\mathrm{a}$ & $\mathrm{b}$ \\
\hline \multirow{2}{*}{ Purple rice } & Cooked & 92.65 & 2.01 & 6.01 \\
& Uncooked & 89.49 & 5.72 & 3.92 \\
\hline \multirow{2}{*}{ Brown rice } & Cooked & 96.93 & -0.34 & 1.08 \\
& Uncooked & 96.92 & -0.32 & 0.99 \\
\hline \multirow{2}{*}{ Polished rice } & Cooked & 97.02 & -0.33 & 0.84 \\
& Uncooked & 96.82 & -0.30 & 0.97 \\
\hline
\end{tabular}

Values are the means of three replicates.

uncooked purple rice grain show the typical peak of anthocyanin at $530 \mathrm{~nm}$.

The antioxidative activity of the various alcoholic beverages was determined. The DPPH radical scavenging activity of the alcoholic beverages made from purple rice was much higher than that of the beverages made from ordinary brown rice and polished rice (Fig. 5). The lipid peroxidation inhibitory activity of the alcoholic beverages was also determined.
The alcoholic beverages made from purple rice grain showed strong inhibitory activity of lipid peroxidation. Spectrophotometric analysis revealed that the specific absorbance at 530 $\mathrm{nm}$ of the alcoholic beverage made from cooked purple rice was drastically decreased.

Oki et al. (2002) reported that the dominate DPPH-radical scavengers in purple-fleshed sweet potato "Ayamurasaki" were anthocyanins with peonidin aglycone rather than 

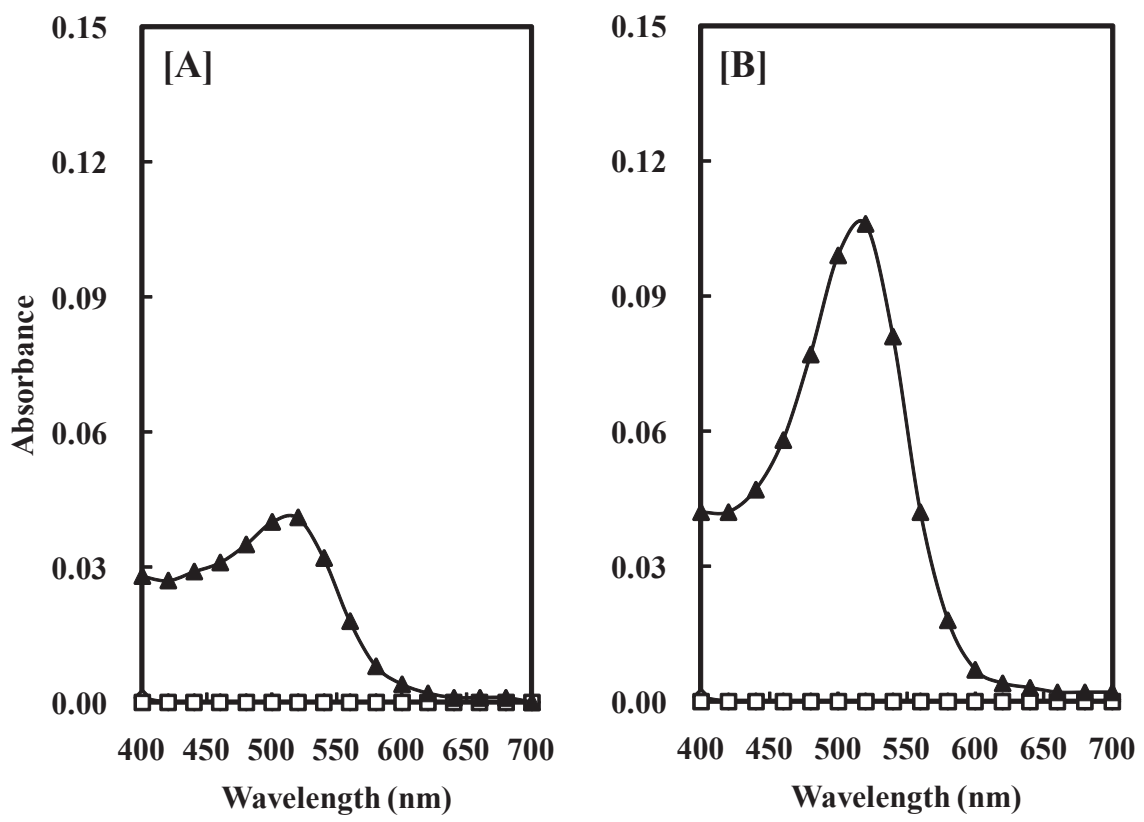

Fig. 4. Absorption spectra of alcoholic beverages made from various rice grains with [A] or without [B] cooking. $\boldsymbol{\Delta}$, purple rice; $\square$, brown rice; $\diamond$, polished rice. Values are the mean of three replicates.
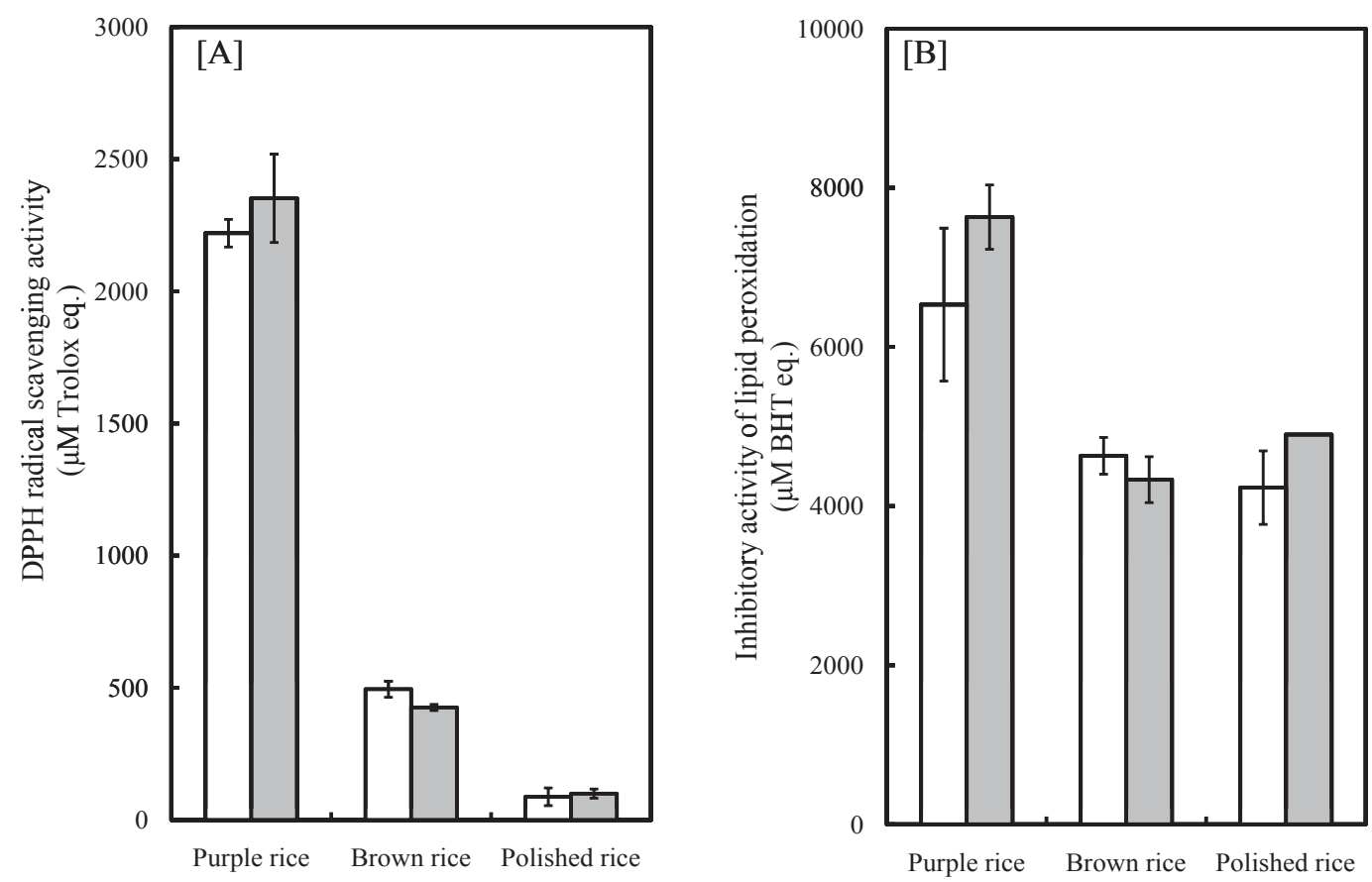

Fig. 5. Antioxidative activity of alcoholic beverages made from various rice grains. Open bars, fermentation with cooking; gray bars, fermentation without cooking. Values are the mean of three replicates \pm SD. [A], DPPH radical scavenging activity ( $\mu \mathrm{M}$ Trolox equivalent); [B], Inhibitory activity of lipid peroxidation ( $\mu \mathrm{M}$ BHT equivalent).

phenolic compounds. However, in the case of alcoholic beverage made from purple rice, DPPH-radical scavenging activity was not related to the amounts of anthocyanins present. Therefore, we surmised that differences in radicalscavenging activity of alcoholic beverages made from purple rice wine were related to the amounts of phenolic compound. Furthermore, we confirmed the possibility that DPPH- radical-scavengers in alcoholic beverages were stable during cooking, and that purple rice contained greater amounts than other rice grains.

Chen et al. (1998) reported that peptides with lipid peroxidation inhibitory activity did not have DPPH radicalscavenging activity. It is also possible that the antioxidant substances in each alcoholic beverage need to be identified, 
as they may differ. Therefore, we think it likely that the lipid peroxidation inhibitory substances were stable during cooking, and that purple rice contained comparative greater amounts than other rice gains. It was necessary to identify the antioxidant substances in alcoholic beverages made from various rice grains.

Rice wine made from purple rice grain shows antioxidative activity. We would like to improve the taste and aroma of purple rice wine, producing a fine alcoholic beverage with inherent physiological advantages.

Acknowledgements The authors are grateful to Ms. Sachie Onoue and Mr. Hideharu Inoue for their skillful assistance.

\section{References}

Boyles, M.J. and Wrolstad, R.E. (1993). Anthocyanin composition of red raspberry juice: Influences of cultivar, processing, and environmental factors. J. Food Sci., 58, 1135-1141.

Chen, H.-M., Muramoto, K., Yamauchi, F., Fujimoto, K. and Nokihara, K., (1998). Antioxidative properties of histidine-containing peptides designed from peptide fragments found in the digests of a soybean protein. J. Agric. Chem., 46, 49-53.

Furuta, S., Suda, I., Nishiba, Y. and Yamakawa, O. (1998). High tert-butylperoxyl radical scavenging activity of sweet potato cultivars with purple flesh. Food Sci. Technol. Int. Tokyo, 4(1), 33-35.

Hamasaka, T., Kumazawa, S., Fujimoto, T. and Nakayama, T. (2004). Antioxidant activity and constituents of propolis collected in various areas of Japan. Food Sci. Technol. Res., 10, 86-92.

Miyazaki, K., Makino, K., Iwadate, E., Deguchi, Y. and Ishikawa, F. (2008). Anthocyanins from purple sweet potato lpomoea batatas cultivar ayamurasaki suppress the development of antherosclerotic lesions and both enhancements of oxidative stress and soluble vascular cell adhesion molecule-1 in apolipoprotein E-deficient mice. J. Agric. Food Chem., 56, 11485-11492.

Nelson, T. (1944). A photometric adaptation of the Somogyi method for the determination of glucose. J. Biol. Chem., 153, 375-380.

Saigusa, N., Teramoto, Y., Ueda, S. and Yoshizawa, K. (1994). Effects of $\beta$-glucosidase activity on the characteristics of aromatic red rice wine. J. Inst. Brew., 100, 159-162.

Singleton, V.L., Orthofer, R. and Lamuela-Raventos, R.M. (1999). Analysis of total phenols and other oxidation substrates and antioxidants by means of Folin-Ciocalteu reagent. Methods Enzymol., 299, 152-178.

Somogyi, M. (1952). Notes on sugar determination. J. Biol. Chem., 195, 19-23.

Suda, I., Furuta, O., Nishiba, Y., Yamakawa, O., Matsugano, G. and Sugita, K. (1997). Reduction of liver injury induced by carbon tetrachloride in administered purple-colored sweet potato juice. Nippon Shokuhin Kagaku Kogaku Kaishi, 44(4), 319-324 (in Japanese).

Teramoto, Y., Saigusa, N., Ueda, S., and Yoshizawa, K. (1994). Production and characteristics of red rice sake. J. Inst. Brew., 100, 3-6.

Teramoto, Y., Saigusa, N., Yoshida, Y. and Ueda, S., (1994). Ethanol fermentation of various red rices without cooking. J. Inst. Brew., 100, 7-9.

Teramoto, Y., Saigusa, N., Ueda, S. and Yoshizawa, K. (1994). Effects of the cooking process on the characteristics of aromatic red rice wine. J. Inst. Brew., 100, 155-157.

Yamaguchi, T., Takamura, H., Matoba, T. and Terao, J. (1998). HPLC method for evaluation of free radial-scavenging activity of foods by using 1,1-diphenyl-1-2-picrylhydrazyl. Biosci. Biotechnol. Biochem., 62, 1201-1204.

Yoshimoto, M., Okuno, S., Yoshinaga, M., Yamakawa, O., Yamaguchi, M. and Yamada, J. (1999). Antimutagenicity of sweet potato (Ipomoea batatas) root. Biosci. Biotechnol. Biochem., 63(3), 537-541. 